\title{
Методы и устройства для оценки пригодности сортов и гибридов картофеля к механизированной уборке
}

\section{В.Н. Зернов, С.Н. Петухов}

В представленном материале на основе анализа литературных источников доказано генетическое наследование устойчивости сортов картофеля к механическим повреждениям, показано влияние повреждений клубней на их качество и сохранность, а также необходимость разработки методики и устройств, позволяющих вести направленную селекцию сортов, пригодных к механизированной уборке. Проанализированы методы и средства оценки пригодности сортов и гибридов картофеля к механизированной уборке. Выявлено, что истинная оценка повреждаемости сортов картофеля определяется в полевых условиях при реальной машинной уборке.

Ключевые слова: механические повреждения, наследование устойчивости, методы оценки, устройства, пригодность сортов и гибридов, механизированная уборка.

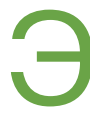
ффективность картофелеводства в значительной степени зависит от качества семенного материала. К основной составляющей, создающей генетическую основу семян, относится селекция. Различные сорта картофеля, кроме продолжительности вегетационного периода и урожайности, обладают такими наследственными (генетическими) признаками, как выход крахмала, устойчивость к болезням и вредителям, неблагоприятным факторам среды и т.д. В связи с комплексным внедрением машинных технологий по возделыванию, уборке и послеуборочной доработке картофеля, а также длительностью хранения клубней до их реализации или посадки, к картофельному растению кроме перечисленных генетических признаков предъявляются дополнительные наследственные требования - устойчивость к механическим нагрузкам при механизированном возделывании. Доказано, что генотип устойчивости клубней картофеля к механическим повреждениям имеет большее значение чем факторы окружающей среды [1, 2].

Ведение селекции на повышенную выносливость картофеля к механическим нагрузкам было вызвано все возрастающим механическим воздействием на клубни при возделывании, уборке и закладке картофеля на хранение. Механические повреждения имеют наиболее важ- ное значение из всего многообразия повреждений клубней картофеля, поскольку такие организмы, как бактерии и грибы получают доступ к тканям клубней только при механических повреждениях. Поэтому распространение инфекции зависит от наличия механических повреждений, а устойчивость к последним обеспечивает защиту клубней от болезней. Кроме того, механические повреждения приводят к дополнительным потерям в виде увеличения отходов при использовании картофеля в пищевых целях. К тому же картофель с механическими повреждениями быстро теряет в весе за счет усиленного испарения с поврежденной поверхности [3].

Проведенный анализ существующих средств для оценки устойчивости клубней картофеля к механическим нагрузкам при механизированной уборке показал, что с точки зрения имитации работы картофелеуборочных машин и приемлемых для лабораторной установки габаритах, наибольший интерес представляют барабанные установки $[4,5]$. Установка представляет собой прутковый барабан с лопастями. Составляются программа и методика проведения испытаний образцов, имитирующая процесс комбайновой уборки. Оценка образцов клубней картофеля на устойчивость к механическим нагрузкам производится следующим образом. В барабан за- кладывают партию испытуемых клубней в количестве 8-10 штук и начинают вращать барабан. Клубни поднимаются лопастями на определенную высоту и под собственным весом падают на прутковую поверхность барабана. После определенного количества оборотов барабан останавливают, вынимают клубни и производят оценку их повреждения согласно существующих отраслевых стандартов. С помощью подобной конструкции можно имитировать перепады клубней с одного рабочего органа комбайна на другой, а это, как показывают исследования, составляет около $65 \%$ повреждений от общего их количества при комбайновой уборке картофеля [6].

Стремясь в устройство-определитель устойчивости клубней картофеля к механическим повреждениям добавить к имитации перепадов и имитацию сепарирующих рабочих органов комбайна, ряд исследователей перешли к разработке более сложных (элеваторных) типов определителей повреждений [7, 8, 9, 10].

Элеваторные типы имитаторов уборочных машин усложняют конструкцию и сводят сами устройства к комбайнам в миниатюре, что иска-

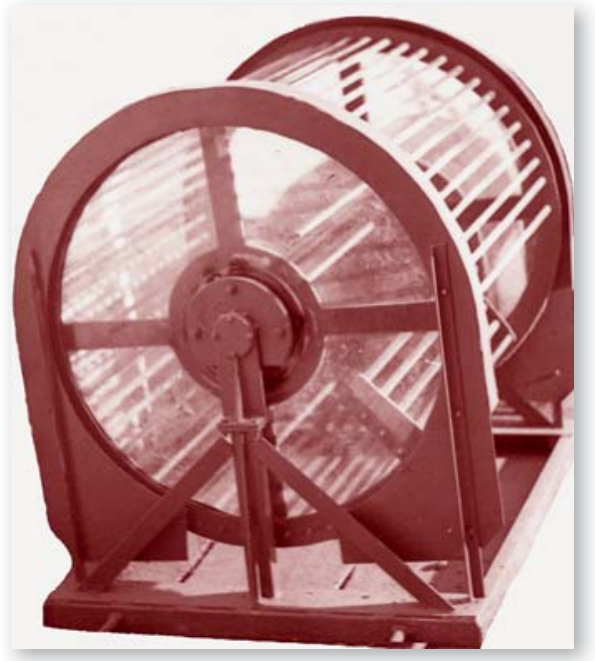

Определитель повреждений барабанного типа 


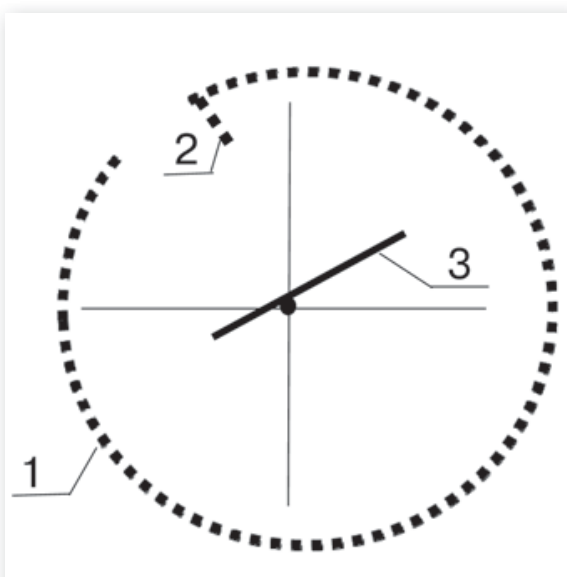

Рис. 1. Схема устройства для определения повреждаемости клубней: 1 - прутковый барабан; 2 - лопасть; 3 - решетка

жает реальные нагрузки на клубни при их использовании. Кроме того, элеваторные имитаторы повреждений имеют значительно большие габариты в сравнении с барабанными устройствами.

В 80-е годы прошлого столетия в ОКБ НИИ картофельного хозяйства, с целью добавления к имитации перепадов на рабочих органах картофелеуборочных машин имитацию элеватора картофелеуборочного комбайна (т.е. сепарирующих рабочих органов), было разработано устройство барабанного типа (рис. 1) [11].

Устройство работает следующим образом. В прутковый барабан (1) помещают порцию испытуемых клубней картофеля. При вращении барабана по часовой стрелке лопасть (2) захватывает клубни и поднимает их на заданную высоту, которая устанавливается за счет изменения угла наклона лопасти. При дальнейшем вращении барабана клубни падают на решетку (3) с продольными прутками, имитируя перепады. С решетки (3) клубни скатываются на прутки барабана (имитация перепада) по которым они перекатываются до возврата на лопасть (2), имитируя при этом элеватор картофелеуборочного комбайна. Далее цикл повторяется. При отсчете заданного количества циклов барабан реверсируется и клубни высыпаются через окно в приемную тару, движение барабана автоматически выключается.

В устройстве, показанном на рисунке 1, к имитации перепадов клубней с одного рабочего органа комбайна на другой, добавлена имитация сепарирующих рабо- чих органов комбайна, а это, как показывают ранее проведенные исследования, приближает количество поврежденных клубней на имитаторе к 95\% повреждаемости картофеля от общего количества повреждений при комбайновой уборке [6]. По видам повреждений в указанных устройствах в полной мере будут имитироваться потемнение мякоти - 70\% от общего числа повреждений [6], вызываемое ударными нагрузками на сепарирующих рабочих органах комбайна и перепадах. В некоторой степени будут имитироваться трещины, вырывы мякоти и обдир кожуры в результате ударных нагрузок, скольжения клубней по пруткам устройства и взаимодействия их между собой. Повреждения, наносимые колесами трактора и подкапывающими рабочими органами комбайна (раздавленные, разрезанные и, частично, клубни с вырывом мякоти) вышеназванные устройства не имитируют, а это на комбайнах составляет около 5\% от общего числа повреждений.

Имитатор повреждений барабанного типа более компактен по своим габаритам, прост по конструкции, удобен в эксплуатации и позволяет варьировать величинами механических нагрузок на испытуемые клубни, приближая их к работе современных картофелеуборочных машин.

При разработке принципиальной схемы устройства для оценки устойчивости клубней картофеля к механическим нагрузкам, получаемым во время работы современных картофелеуборочных машин, за основу был взят имитатор барабанного типа конструкции НИИКХ им. А.Г. Лорха.

Современные картофелеуборочные комбайны работают более мягко, большинство рабочих органов имеют эластичные покрытия. В их конструкциях все больше используются пальчиковые сепараторы (отделители почвы и растительных остатков) и пальчиковые транспортеры.

На рисунке 2 показана принципиальная схема предлагаемого имитатора повреждений, возникающих на клубнях картофеля при уборке современными картофелеуборочными машинами.

Устройство состоит из барабана с обрезиненными прутками (1), с лопастью (2) и открытым за ней окном для загрузки и выгрузки партии испытуемых клубней. Внутри барабана над его осью установлена пальчи- ковая горка (3), позволяющая менять угол наклона.

Устройство работает следующим образом. В прутковый барабан (1) помещают порцию испытуемых клубней картофеля. При вращении барабана по часовой стрелке лопасть (2) захватывает клубни и поднимает их на заданную высоту, которая устанавливается за счет изменения угла наклона лопасти. При дальнейшем вращении барабана клубни падают на пальчиковую горку (3), имитируя перепады и перемещение клубней по ежным (пальчиковым) транспортерам комбайна. С пальчиковой горки (3) клубни скатываются на обрезиненные прутки барабана (имитация очередного перепада) по которым они перекатываются до возврата на лопасть (2), имитируя при этом элеватор картофелеуборочного комбайна. Далее цикл повторяется. При отсчете заданного количества циклов барабан реверсируется и клубни высыпаются через окно в приемную тару, движение барабана автоматически выключается.

Расчетное количество циклов определяется, исходя из соответствия числа перепадов и пройденного пути клубнями картофеля по элеватору картофелеуборочной машины и имитатора. Экспериментально количество циклов для каждого вида картофелеуборочных машин уточняется методом тарировки при уборке картофеля в поле. Высота перепадов на имитаторе лимитируется конструктивными размерами барабана и должна соответствовать перепадам на картофелеуборочных машинах. Более тонкая настройка имитатора повреждений под конкретную уборочную машину достигается из-

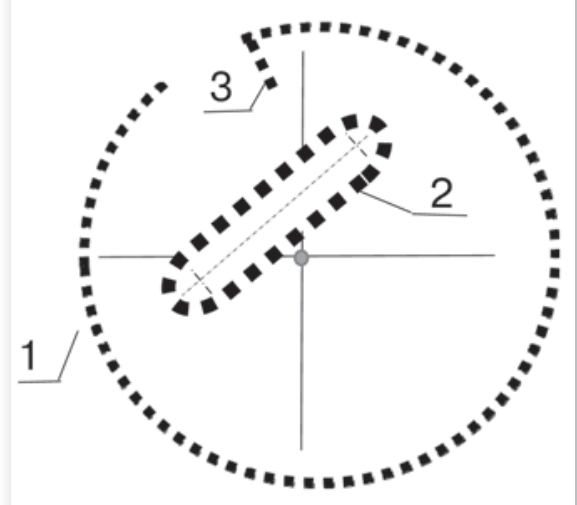

Рис. 2. Принципиальная схема определителя повреждаемости клубней современными картофелеуборочными машинами: 1 - прутковый барабан; 2 - лопасть; 3 - пальчиковая горка 
менением угла поворота лопасти (2) и расположением пальчиковой горки (3) имитатора.

Разработка конструкции и изготовление устройства в соответствии с предложенной принципиальной схемой, его тарировка под современные картофелеуборочные машины и отработка методики оценки устойчивости сортов картофеля к механизированной уборке позволит вести направленную селекцию сортов, пригодных к механизированному возделыванию.

Применение достоверной методики позволит оценивать пригодность сортов и гибридов к механизированной уборке на ранних этапах селекционно-семеноводческих работ, а в массовом производстве определить сроки комбайновой уборки картофеля, исключающие массовые потери клубней при хранении.

Разработанная принципиальная схема устройства в виде барабана-имитатора с заменой решета на пальчиковую горку позволит при соответствующей тарировке более чем на 95\% имитировать механические нагрузки на клубни картофеля при уборке современными картофелеуборочными машинами. Имитатор повреждений позволяет варьировать величинами механических нагрузок на клубни картофеля, приближая их к работе современных картофелеуборочных машин. Испытания картофеля на устойчивость к механическим повреждениям позволит на ранних этапах селекционного процесса дать оценку новым сортам и гибридам по этому важному показателю.

\section{Библиографический список}

1.Мишхожев А.А. О влиянии сортовых особенностей на повреждаемость клубней картофеля // Novalnfo.Ru. 2016. № 40. T. 2. С. 21-23.

2.Морозова Н.Н. и др. Наследование устойчивости к механическим повреждениям клубней картофеля в потомстве от разных типов скрещивания // Сб. трудов НИИКХ. Селекция и биотехнология. М., 1990. С. 43-49.

3.Габаев А.Х., Мишхожев А.А. Сортовые особенности и их влияние на устойчивость клубней к механическим повреждениям // Актуальные вопросы развития аграрной науки в современных экономических условиях: материалы IV Междунар. науч.- практ. конф. молодых ученых. ФГБНУ «ПНИИАЗ", 2015. С. 215-216.

4.Weber I, Graesert V. \& Ulrich G. Eine Methode zur Prufeend fon Zuchtmaterial auf Widerstandsfahigkeit gegenuber mascineller Belastung 8-th Triennial Conf Eur. Ass. Pot. Res. Munchen, 1981. 108-109.
5.Сийм Я.М. Определение повреждаемости клубней // Картофель и овощи. 1977. № 2. С. 18.

6.Туболев С.С., Шеломенцев С.И., Пшеченков К.А., Зейрук В.Н. Машинные технологии и техника для производства картофеля. М.: Агроспас, 2010. $312 \mathrm{c}$

7.Кузьмин А.В., Буянтуев В.Э., Захарко А.В. Обоснование параметров технических средств для оценки повреждаемости клубней // Проблемы механики современных машин: материалы V междунар. конф. Улан-Удэ, 2012. С. 231-234.

8.Кузьмин А.В., Болохоев В.С., Вамбуева Э.Б. Особенности технических средств для оценки повреждаемости клубней // Инновационные технологии в науке и образовании: сборник трудов международной НПК (г. Улан-Удэ, 1618 сентября 2011г.) Улан-Удэ: Изд-во БГУ, 2011. С. $88-91$

9.Кузьмин А.В., Болохоев В.С. Определение режимов работы определителя повреждаемости клубней // Сборник научных трудов. Серия: Технология и средства механизации в АПК. Вып. 8. Улан-Удэ: Изд-во ВСГУТУ, 2012. С. 74-76.

10.Кузьмин А.В., Остроумов С.С., Болохоев В.С. Манталаева С.Л. Параметры определителя повреждаемости клубней картофеля // Вестник ВСгУтУ. 2015. № 5. C. $18-23$.

11.А.С. СССР № 1232998, G01N 3/32. Устройство для определения повреждаемости корнеклубнеплодов / Н.А. Скверский, В.Н. Зернов, Б.О. Кузьмин, П.Б. Кузьмин, И.П. Вялов; заявитель Опытноконструкторское бюро Научно-исследовательского института картофельного хозяйства; опубл. 23.05.1986, Бюл. № 19 .

\section{Об авторах}

Зернов Виталий Николаевич, канд техн. наук, в.н.с., Федеральное государственное бюджетное научное учреждение «Федеральный научный агроинженерный центр ВИМ».

E-mail:vim@vim.ru.
Петухов Сергей Николаевич, канд. с. - х. наук, в.н.с., Федеральное государственное бюджетное научное учреждение «Федеральный научный агроинженерный центр ВИМ».

E-mail:vim@vim.ru.

Methods and devices for an estimation of potato varieties and hybrids suitability

to a mechanical harvesting

V.N. Zernov, PhD, leading research fellow,

All-Russian institute of Mechanization.

E-mail:vim@vim.ru.

S.N. Petukhov, PhD, leading research

fellow, All-Russian institute of

Mechanization.E-mail:vim@vim.ru.

Summary. In the presented material on the basis of the analysis of references genetic inheritance of a potato varieties resistance to mechanical damages is proved, influence of damages of tubers on their quality and suitability for storage, and also necessity of working out of a technique and the devices is shown, allowing to conduct a controlled breeding of varieties, suitable to a mechanical harvesting. Methods and equipments for an estimation of potato varieties and hybrids suitability to a mechanical harvesting are analysed. It is proven that true rating of potato varieties damageability is defined in field conditions at practical machine harvesting.

Keywords: mechanical damages, resistance inheritance, methods of an estimation, the device, suitability of varieties and hybrids, a mechanical harvesting.

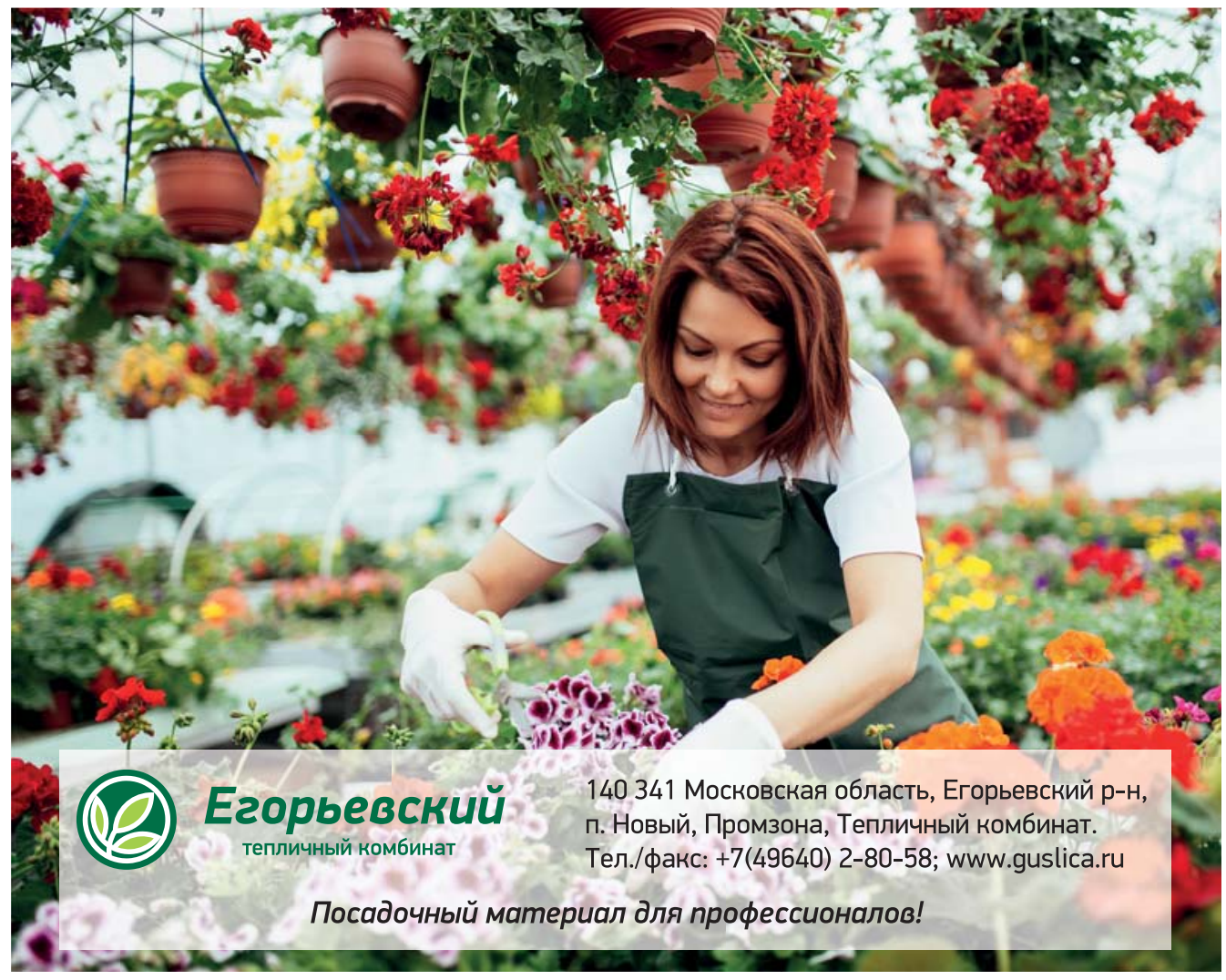

